\section{THE VERTICAL DISTRIBUTION OF THE METEOROLOGICAL ELEMENTS ABOVE THE ATLANTIC.}

IN a previous article (vol. 1xxiii. pp. 54-56) we described our expedition to the tropics, and gave the results of the observations with balloons and on mountains, so far as they related to the movements of the upper currents. In the present article we will consider the observations with kites, which furnished nearly continuous records of temperature, humidity, and wind velocity from sea-level to a height of 2300 metres, and the direct observations to a greater height which Mr. Clayton obtained in ascending and descending the tropical peaks on the islands of Teneriffe and Fogo. During a voyage of the White Star steamer Romanic, from Boston to Gibraltar, Mr. Clayton executed six kite-flights, and on board the steam-yacht Otaria, between latitudes $37^{\circ}$ and $10^{\circ} \mathrm{N}$., longitudes $16^{\circ}$ and $3 \mathrm{I}^{\circ}$ W., with the assistance of M. Maurice, seventeen kite-flights were made, besides two in the harbour of Santa Cruz to investigate the sea breeze, and one in latitude $43^{\circ} 43^{\prime}$ N., longitude $8^{\circ} 43^{\prime}$ W., for the study of the changes in the free air produced by the total solar eclipse. The observations obtained at the height of 1000 metres, compared with those at sea-level, are given in Tables i. and ii. The first table contains the observations made in a general east and west direction between longitudes $69^{\circ}$ and $16^{\circ} \mathrm{W}$., latitudes $42^{\circ}$ and $33^{\circ} \mathrm{N}$. West of the Azores, that is to say, on the westward slope of the permanent area of high pressure, the decrease of temperature with height was slow, there being two cases out of the four in which the temperature increased immediately above the ocean, the average decrease in the thousand metres being but $0^{\circ} \cdot 4 \mathrm{I} C$. On the eastern and southern slopes of the high pressure the temperature decrease approached the adiabatic rate, amounting on the average to $0^{\circ} .73 \mathrm{C}$. per hundred metres. The relative humidity diminished with altitude over the western barometric slope and increased in the observations obtained over the eastern slope, while the wind veered and increased with altitude in the former locality and backed with diminishing velocity in the latter. Fig. I shows the typical vertical distribution of the meteorological elements to the westward of the Azores.

The observations made at the height of 1000 metres and at sea-level in a general north and south direction. between latitudes $35^{\circ}$ and $10^{\circ} \mathrm{N}$., appear in Table ii. It will be seen that the temperature decrease is most rapid (average $0^{\circ} .78$ C. per 100 metres) near the northern and southern limits of the north-east trades, and is least rapid within the trade-wind region (average $0^{\circ} .07$ C.), due to the presence of strata with inverted temperature gradients, of which a typical example, with the corresponding changes of humidity, is shown in Fig. 2. The relative humidity varies inversely with the temperature, being slightly greater at rooo metres just outside the trade wind, and much less at this height within the trade belt. While the observations of wind do not indicate any marked deviation from the north-easterly direction, there is a considerable decrease in the velocity of the trade with increasing height.

Mr. Clayton's study of the data collected in the tropics points to the existence of three strata between the sea and 4000 metres, characterised by differences in tempera-

TABLE I.-Conditions at sea-level and at 1000 metres over the Atlantic, between Longitudes $69^{\circ}$ and $16^{\circ}$ West.

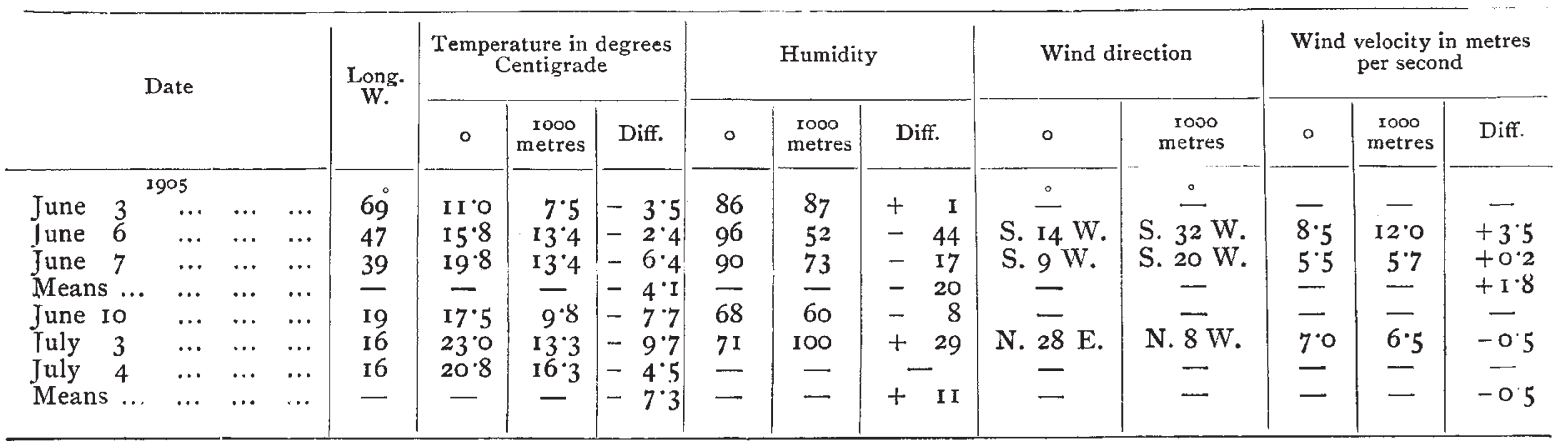

TABLE II.-Conditions at sea-level and at 1000 metres over the Atlantic, between Latitudes $35^{\circ}$ and $10^{\circ}$ North.

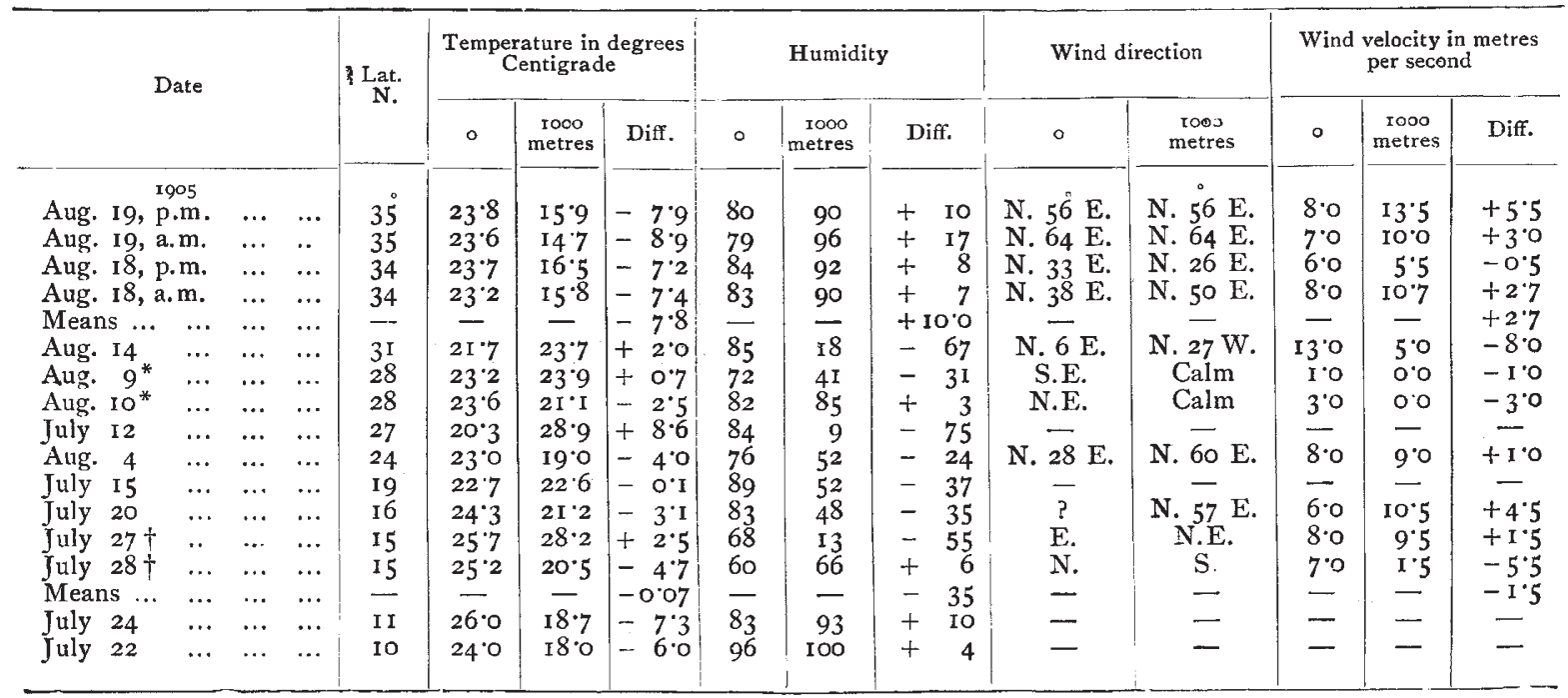


ture, humidity, cloudiness, and wind. The trade wind, limited to about rooo metres in thickness, varies in direction between north and east, is damp, and usually carries cumulus or strato-cumulus clouds in its upper portion. Above the surface trade is a current about 2000 metres in depth, varying in direction between north-east and northwest, but coming always from a direction to the left of the lower wind when facing it. This current is extremely dry and potentially warm, and its velocity is usually much greater than that of the lower wind. At their plane of meeting occurs a belt of calms or light winds with a marked inversion of temperature, and this rise of temperature is

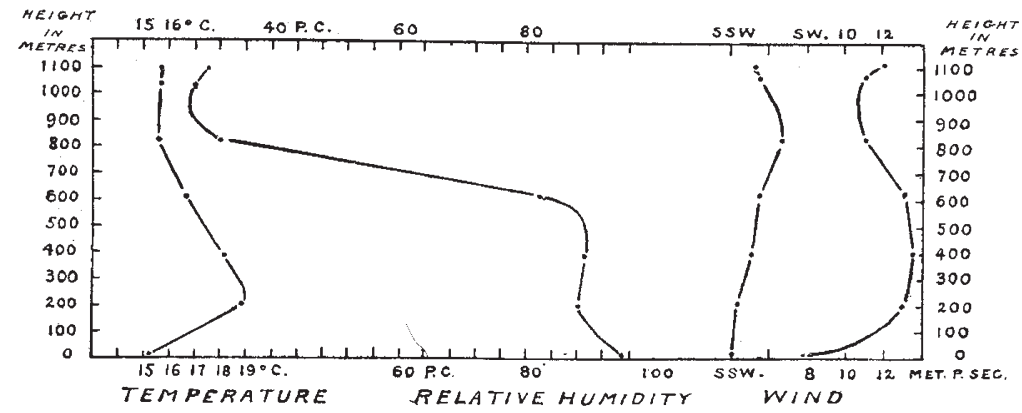

FIG. I.-Vertical Distribution of Temperature, Humidity and Wind, June 6, 1905 ; Lat. $40^{\circ} 33^{\prime} \mathrm{N}$., Long. $46^{\circ} 43^{\prime} \mathrm{W}$.

accompanied by a very decided fall of humidity, the relative humidity in some cases falling to nearly zero. The third stratum, which begins at a height of about 3000 metres, moves from a direction varying between east and south or south-west, being generally from the east in equatorial regions and from the south between latitudes $15^{\circ}$ and $30^{\circ} \mathrm{N}$. As observed on the Peak of Teneriffe, this stratum was dry in its lower portion, but had a slightly larger vapour contents than the air immediately below. Alto-cumulus and alto-stratus clouds were seen floating in it at a height of perhaps 4000 metres or 5000 metres, and from them light sprinkles of rain fell occasionally. In passing into this upper current- a rise of temperature was noted, but this was less marked than

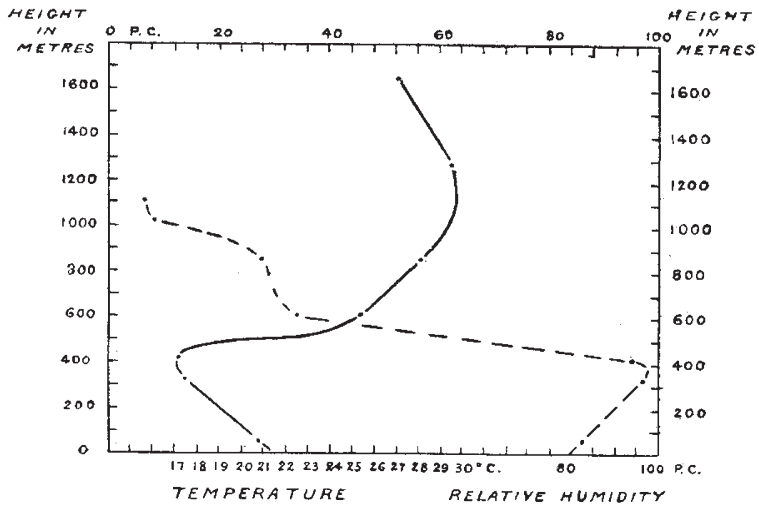

FIG 2.-Vertical Distribution of Temperature and Humidity, July I2, 1905 ; Lat. $27^{\circ} 30^{\prime}$ N., Long. $16^{\circ} 48^{\prime} \mathrm{W}$.

the rise encountered above the surface trade. Mr. Clayton also deduces the following facts from the observations:(I) the bases of the cumulus clouds are low over the ocean, rarely exceeding 500 metres; (2) the height of the inverted temperature gradient varies from day to day between 300 metres and 1500 metres, with a probable average of rooo metres, and its height also appears to undergo a diurnal change, being lowest at night or in the morning and highest in the afternoon; (3) the adiabatic rate of decrease of temperature prevails over the ocean at night as well as during the day.

The vertical distribution of temperature and humidity NO. I 897 , VOL. 73] revealed by our observations up to a height of 4000 metres agrees in general with that found by Prof. Hergesell during the cruises of the Prince of Monaco's yacht in 1904 and 1905 (see Comptes rendus de l'Académie des Sciences, January 30, I905, and Bulletin du Musée Océanographique de Monaco, November 30, 1905). From the latter publication it is interesting to learn that a balloon, liberated by Prof. Hergesell on August 7 last far to the westward of the Canary Islands, indicated the same currents which were found by us in the neighbourhood of these islands, since it met the south-east and south-west winds above the north-east trade. It is significant that this balloon reached a greater height than did the other balloons, which showed winds having a northerly component. We perceive that Prof. Hergesell no longer denies the possibility of an upper antitrade in a lower latitude than the Canaries, but now simply states that in the central part of the Atlantic he found almost exclusively north-west winds, from which he concludes that the route followed by the currents bringing the air from the equator appears to be less simple than had been supposed, and seems to depend on the relative positions of the continents and oceans. The study of the daily isobars over the ocean, which was first made under the direction of Le Verrier in 1864 , showed that the pressure is not distributed in uniform belts, and that the isobars are everywhere deflected by the influence of temperature distribution dependent upon the land and sea, relations which were demonstrated by $M$. Teisserenc de Bort's study of isonormals more than twenty years ago. Hence it would appear that there are certain regions where the anti-trade is more regular than elsewhere, the zone between the Cape Verde and Canary Islands being no doubt one of these; but this view is quite contrary to the idea that the south-east and south-west winds observed in the upper atmosphere near these islands, and hitherto accepted as proof of the anti-trade, are due to local influences, which Prof. Hergesell still affirms to be true.

A. L. Rotch.

L. Thisserenc de Bort.

\section{THE TRANSFORMATIONS OF ROCK-MASSES.}

THE study of the changes which rock-masses undergo under natural conditions is in itself by no means an inconsiderable branch of geology, and its pervading importance throughout the whole field of the science brings it continually to the front in stratigraphical as well as petrological research. The literature of the subject is a large one, but until now no serious attempt has been made to deal fully and comprehensively with the principles and phenomena of metamorphism as a whole. Prof. van Hise's wide experience in the Lake Superior region and elsewhere has made him well fitted for a task to which he has devoted seven years of labour; and the outcome of that labour, as represented in the massive volume before us, will have a permanent value for all who come after him in this field.

This treatise, as we are told in the preface, is " an attempt to reduce the phenomena of metamorphism to order under the principles of physics and chemistry, or, more simply, under the laws of energy." Metamorphism is understood to include all alterations of all rocks by all processes. This extension of customary usage may be defended on logical grounds, and it has the advantage of constantly keeping in view the essential unity underlying the complex operations of nature; but it involves a corresponding enlargement of the subject-matter. The scrupulous-almost relentless--manner in which the author follows out in every detail the general scheme of treatment laid down further swells the bulk of the volume, and, brought out in the handsome style which characterises the produc-

1 "A Treatise on Metamorphism." By Charles Richard van Hise. (Monographs of the U.S. Geological Survey, vol. xlvii.) Pp. 1286 and I 3 plates. (Washington, 1904.) 